\title{
APRESENTAÇÃO DO SISTEMA DE LOCAÇÃO DE VEÍCULOS CARLUGA
}

\author{
Melissa Heringer Silveira ${ }^{1}$ \\ Vinício Fragoso Mendes ${ }^{2}$ \\ Thiago Vieira de Souza Eleutério ${ }^{3}$ \\ Pedro David Netto Silveira ${ }^{4}$ \\ Flávio Pavesi Simão 5
}

Resumo: O objetivo deste trabalho é apresentar um sistema denominado CarLuga para gerir locações de veículos. Desenvolvido para ser utilizado em plataformas desktop, com uma máquina virtual Java em execução, este sistema possui as funcionalidades de cadastro, visualização, locação e devolução. Para proteger os dados, foi utilizada a criptografia MD5. Os dados inseridos no sistema são salvos em um servidor de banco de dados MySQL. As informações de aluguéis armazenadas no sistema é uma forma de diminuir a quantidade de documentos impressos e agilizar consultas. A ferramenta CarLuga mostra-se eficiente ao compactar informações em um único local, promovendo a diminuição de material impresso, gerando, desta forma, uma economia na aquisição de material de consumo na empresa podendo, este recurso, ser redirecionado para promover melhorias na mesma. A segurança proporcionada pela criptografia gera maior confiança por parte dos usuários, em que as atividades desenvolvidas são pessoais e restritas, sendo o acesso definido por perfil de usuário.

Palavras-chave: Automatização; Criptografia; Tecnologia.

\footnotetext{
${ }^{1}$ Tecnologia em Análise e Desenvolvimento de Sistemas/Instituto Federal do Espírito Santo - Campus de Alegre, Brasil. E-mail: melissa.heringer@gmail.com.

${ }^{2}$ Tecnologia em Análise e Desenvolvimento de Sistemas/Instituto Federal do Espírito Santo - Campus de Alegre, Brasil. E-mail: vinicio0408@gmail.com.

${ }^{3}$ Tecnologia em Análise e Desenvolvimento de Sistemas/Instituto Federal do Espírito Santo - Campus de Alegre, Brasil. E-mail: thiagoamamuitojesus@hotmail.com.

${ }^{4}$ Tecnologia em Análise e Desenvolvimento de Sistemas/Instituto Federal do Espírito Santo - Campus de Alegre, Brasil. E-mail: pedro.silveira@ifes.edu.br.

${ }^{5}$ Tecnologia em Análise e Desenvolvimento de Sistemas/Instituto Federal do Espírito Santo - Campus de Alegre, Brasil. E-mail: fpsimao@ifes.edu.br.
} 